\title{
Are refugees' labour market outcomes different from those of other migrants? Evidence from the United Kingdom in the 2005-2007 period
}

\author{
Isabel Ruiz \\ Harris Manchester College \\ University of Oxford \\ isabel.ruiz@hmc.ox.ac.uk \\ Carlos Vargas-Silva (contact author) \\ Centre on Migration, Policy and Society \\ University of Oxford \\ 58 Banbury Road \\ Oxford \\ Ox2 6QS \\ carlos.vargas-silva@compas.ox.ac.uk
}

Thanks to Sin Yi Cheung, Cinzia Rienzo and Madeleine Sumption for helpful comments and suggestions on an earlier draft of this paper. The usual disclaimer applies. The SNR and LFS are both available from the UK Data Service. Neither the UK Home Office nor the UK Data Archive has responsibility for analysis in this study. 


\title{
Are refugees' labour market outcomes different from those of other migrants? Evidence from the United Kingdom in the 2005 - 2007 period
}

\begin{abstract}
We compare the labour market outcomes of recent refugees in the 2005-2007 period with those of other migrants in the UK. We compare refugees with a full sample of migrants and with a sample of recent migrants. Controlling for relevant characteristics we find that eight and fifteen months after the grant of protection refugees have significantly worse outcomes than other migrants, including a lower likelihood of being in employment and higher likelihood of unemployment (i.e. not currently employed, but looking for work). However, twenty-one months after the grant of protection the labour market outcomes of recent refugees are not statistically different from those of recent migrants and the difference with those in the full sample of migrants becomes smaller. Results also show that female refugees are at a substantial economic disadvantage compared to male refugees and other female migrants.
\end{abstract}

Keywords: refugees, migration, UK labour market, integration 
Although asylum application numbers in the UK remain below those in other EU countries, they have increased by $80 \%$ since 2010 , reaching the highest level in over a decade, i.e. 32,000 main applicants in 2015 (Home Office, 2016). The government has also pledged to resettle 20,000 Syrian refugees by 2020. The growth in the UK's new refugee population raises important questions regarding the appropriate policies to support the long-term integration of refugees. Participation in the labour market has consistently been identified as a key factor influencing the overall integration of refugees into the host society (Ager and Strang, 2008). While it is too early to explore the labour market outcomes of Syrians and other recent refugees in the UK, it is possible to shed light on this issue by looking at the employment dynamics of previous refugee cohorts. In this paper we look at refugees who were granted protection in the UK during the 2005-2007 period.

The dynamics of refugee economic integration are likely to differ from those of other of migrants, for various reasons. First, differences in the main motivation to migrate suggest that refugees may face greater challenges in the UK labour market, as they are likely to be less favourably “self-selected” for labour market success than other migrants. Second, asylum seekers in the UK face legal restrictions to access the labour market while their asylum claim is being evaluated (Allsopp el at., 2014). Studies for other countries suggest that labour market inactivity spans can have negative long-term consequences for the economic outcomes of refugees (Fransen et al., 2016). Third, many refugees are unable to produce evidence of previous qualifications (Ager and Strang, 2008). Finally, the majority of UK asylum seekers are housed in disadvantaged neighbourhoods (Phillimore and Goodson, 2006; Stewart, 2012) where there is a lack of access to refugee support and social networks (Zetter et al., 2005).

These differences are important because refugees are likely to have major initial economic disadvantages and, therefore, labour market integration policies that typically work 
for migrants might have to be adjusted to the particular situation and socio-economic characteristics of refugees. However, while there is substantial quantitative evidence on the labour market and overall economic outcomes of migrants in the UK, there is scarce evidence about the specific case of refugees. We know little about the labour market integration of refugees and whether, and how, this process differs from that of other migrants. The purpose of this paper is to increase the knowledge base in this topic by looking at how and whether labour market outcomes such as employment, unemployment and likelihood of working in a high skilled job differ between refugees and other migrants.

The scarcity of studies comparing refugees and other migrants is likely due to the lack of adequate data. There are few datasets that indicate or identify whether the person has or had "refugee status" at some point while in the UK. In this paper we make use of a survey with information about individuals who were successfully granted protection in the UK during the mid-2000s. We explore how the labour market outcomes of these new refugees compare to those of other migrants while controlling for relevant demographic, social and geographic characteristics.

\section{Conceptual background and UK context}

An important consideration for our analysis is the "self-selection" process into migration. It is well-known that migrants do not represent a random sample of the population of the country of origin. The self-selection process for migration is likely to be different for refugees compared to those who migrate primarily for economic reasons (often referred to as “economic migrants”). Those migrating for economic reasons self-select across characteristics which relate to the potential economic gains from migration (Borjas, 1987; Chiswick, 1999). Although economic factors might play a role for those who leave their homes primarily to escape conflict and oppression, it is likely that factors related to security and potential discrimination are more important in the self-selection process. Cafferty et al. 
(1983) suggests that refugees are likely to be "less favorably self-selected for labor market success” than other migrants. For example, economic migrants are more likely than refugees to have skills that are transferable across countries. Based on these differences in selfselection one would expect those who migrate mainly for economic reasons to have better labour market outcomes than those who migrate in order to seek protection (Chiswick, 1999). However, one possible caveat regarding the negative selection of refugees is that, in many cases those with higher levels of education and those with more access to information are the ones more likely achieve legal "refugee status". As such, asylum seekers with successful claims could be highly educated in comparison to asylum seekers with unsuccessful claims and other migrants (Muss, 1997). This could affect the traditional dynamics related to selfselection patterns described above.

The UK granted about 5,000 requests of protection per year during 2005-2007 (main applicants). This includes different grants of protection such as asylum, humanitarian protection, discretionary leave and exceptional leave to remain. As shown in Figure 1, about half of those who were granted protection during this period came from Africa. The main countries of asylum in the UK (i.e. those actually granted protection) during this period were Eritrea, Somalia, Afghanistan, Iran, Zimbabwe, and the Democratic Republic of Congo. In fact, close to $70 \%$ of the grants of protection during that period were to asylum seekers from these six countries. This is very different from the main countries of origin of other migrants in the UK during this period: India, Pakistan, Poland, Germany and Bangladesh.

[Figure 1]

There are two policy considerations that are important when looking at refugees in the UK: initial access to labour markets and geographic location/network externalities. With a few exceptions asylum seekers in the UK cannot work while their asylum claim is being evaluated (Bloch, 2007; Gower, 2016; Phillimore and Goodson, 2006). As a result most 
asylum seekers depend on state support for subsistence. This is a key issue given the evidence which suggests that even short periods of labour market inactivity can lead to a degradation of skills and have psychological discouragement effects (Fransen et al., 2015; General Medical Council, 2014; Raaum and Røed, 2006). This contrasts with the case of most economic migrants who can legally access the labour market upon arrival.

Also, the majority of UK asylum seekers are housed in dispersal accommodation which is assigned directly by the government and there is no possibility for asylum seekers to select the location. Refugees often lack access to support and ethnic networks in these locations (Zetter et al., 2005). The lack of networks can have negative consequences on the initial job search of refugees. Studies for the UK and other countries have found that social networks and ethnic enclaves have a beneficial impact on the economic outcomes of refugees by facilitating access to information about job opportunities (Damm, 2009; Edin et al., 2003; Platts-Fowler and Robinson, 2015). If the asylum seeker is granted protection he/she can look for employment and even move to a different location to have greater access to networks.

\section{[Figure 2]}

However, not everything is negative for refugees. There is evidence which suggests that other differences between refugees and other migrants could result in refugees having better labour market outcomes, particularly in the long-term. For example, some studies have highlighted the importance played by differences in the probability of return between refugees and other migrants (Cortes, 2004). Many refugees do not have the option of returning home, at least in the short-term. The smaller likelihood of return results in a greater incentive to invest in host country skills and human capital (e.g. improving their spoken English) than other migrants for whom there is a greater likelihood of returning home.

Overall, we would expect UK refugees to have worse outcomes than economic migrants in the short-term given differences in self-selection, labour market inactivity spans, 
and lack of initial access to social networks and support. However, refugees eventually have access to the labour market and social networks after receiving protection which suggests that they could catch up with other migrants.

Finally, since we are looking at a particular cohort of refugees, it is also important to highlight the economic situation of the UK during the period of interest as this will have a major impact on labour market outcomes. Figure 2 shows employment rates for all working age residents of the UK and, separately, the rates for the UK and foreign-born groups. The shaded area in Figure 2 is the period of reference for the particular refugee/migrant cohort that we analyse in this paper (more details below). Note that towards the end of that period there is a decline in employment rates, which coincides with the start of the global financial crisis of the late 2000s. Hence, some of the analysis in this paper takes place in a context of deceleration of economic activity and it is not clear whether the findings would hold in other periods (e.g. periods of economic expansion).

\section{Previous evidence on refugee economic outcomes in the UK}

There is limited quantitative evidence on how the economic outcomes of refugees compare to those of other migrants in the UK. The few existing studies seem to suggest that refugees have worse labour market outcomes compared to economic migrants. For example, Bloch (2004) compared outcomes of minority ethnic respondents in the UK Labour Force Survey (LFS) with outcomes of 400 refugees from five countries (Somalia, Iraq, Kosovo, Sri Lanka and Turkey). She finds that refugees have lower employment rates and wages than ethnic minorities in the LFS. The analysis of Bloch (2004) does not include regression analysis. As such, it is not possible to determine whether the differences between refugees and ethnic minorities would hold after controlling for relevant differences between the two groups.

Kausar and Drinkwater (2010) also use the LFS to explore differences in labour market outcomes between economic migrants and refugees in the UK. They find that 
refugees/asylum seekers have worse outcomes in terms of earnings and occupational attainment than other migrants. However, at the time of their analysis there was no way of differentiating migrants in the LFS by original reason for migration. They separate migrants by their likelihood of being refugees based on country of origin and year of arrival. ${ }^{1}$ While this is a novel way of getting around the problem of identification of refugees in the LFS the distinction is arbitrary and the comparison could be somewhat difficult to interpret.

Campbell (2014) uses a recent question in the LFS which asks about the main motivation for their initial migration in order to explore differences in labour market outcomes by original reason of migration to the UK. He finds that males (females) who selected "seeking asylum" as the main reason for original migration are 13 (29) percentage points less likely to be employed than those who selected "for employment". The advantage of this approach is that it is a straightforward way of identifying different types of migrants. However, using the response to this question could be problematic. Some respondents might not want to reveal the real reason for migration for fear of discrimination. This could be particularly problematic if the most successful refugees do not select "seeking asylum" as the main reason for migration. The author does not explore whether this is the case or not.

Overall, some of the challenges faced by other researchers have to do with either accounting for differences in relevant characteristics between refugees and other migrants or in the way refugees are identified in the dataset. In our analysis we are able to identify refugees directly and we control for key differences between refugees and other migrants.

\section{Data}

For the empirical analysis we use data from the Survey of New Refugees (SNR) and the UK Labour Force Survey (LFS). The SNR was commissioned by the UK Border Agency

\footnotetext{
${ }^{1}$ Lindley (2002) also uses a similar approach to identify refugees in the LFS.
} 
(UKBA) then part of the UK Home Office. ${ }^{2}$ The sample only included applicants granted protection between 1 December 2005 and 25 March 2007. There was an initial data collection (i.e. baseline) just after the successful completion of the asylum process (i.e. within one week of the grant of protection). The baseline information was collected for a total of 5,678 new refugees. The questionnaire was in English and in the ten most common languages of refugees at the time. Then there were three rounds of follow-ups 8,15 and 21 months after the asylum decision. These follow-ups include information on labour market activities. As shown in Table 1, there is complete information for 1,555 refugees in the first round, 1,111 refugees in the second round and 839 refugees in the third round. There is information in the three rounds for 729 respondents (i.e. full panel).

[Table 1]

Several studies have analysed the SNR data for various purposes. Daniel at al. (2010) and Cebulla et al. (2010) provide descriptive statistics of the main questions in the survey. Campbell (2012) explored the determinants of refugees' mental health. Cheung and Phillimore (2014) test the relationship between social capital and labour market integration. While these studies have provided important insights on refugee integration in the UK, the analysis did not include a comparison of the outcomes of refugees with those of other migrants.

In order to compare the outcomes of refugees to those of other migrants we use data from the LFS to create a sample of migrants for the same period. The LFS is conducted by the UK Office for National Statistics and it is the main survey of employment conditions in the country. The LFS interviews individuals for 5 consecutive quarters. We only include individuals in the first wave of the LFS in order to avoid repeating the same individuals. The comparable LFS sample for each SNR round includes migrants interviewed in the same

\footnotetext{
${ }^{2}$ The UKBA was superseded by UK Visas and Immigration in April 2013.
} 
quarters in which the different rounds of the SNR were conducted. For instance, the first follow-up round of the SNR was conducted 8 months after the initial decision. For someone with a decision in December 2005 that would be about July 2006 (third quarter of 2006 in the LFS). For someone with a decision in March 2007 that would be November 2007 (fourth quarter of 2007 in the LFS). Table 1 shows the full match between SNR rounds and LFS quarters.

[Table 1]

In the LFS sample we include individuals born in Africa, the Americas, Asia, Europe (other than the UK) or the Middle East. By comparing respondents of the SNR to foreignborn respondents of the LFS we are essentially comparing a sample of new refugees with a sample which is broadly representative of the overall migrant population of the UK. We also compare those in the SNR sample to recent migrants in the LFS, defined as those who have spent less than 10 years in the UK. In all cases we limit the analysis to individuals of working age, defined as 18 to 64 years of age.

\section{Methodology}

The labour market outcomes of interest for the analysis are shown in Table 2. First, we explore whether refugees are more or less likely to be in employment or unemployed (i.e. not currently employed, but looking for work) than migrants in the LFS. Second, we explore differences in the likelihood of being in a high-skilled job defined as a job in the top three occupational categories (Managers and Senior Officials, Professional Occupations, Associate Professional and Technical). We do not explore differences in wage as the SNR does not include this information. Appendix 1 includes the definition of all variables included in the estimation.

As shown in Table 2 for the first round there is a twenty-eight percentage points negative gap in the employment rate between those in the SNR and LFS samples. Likewise, 
there is an eighteen percentage points positive gap in the unemployment rate. When looking at those in employment, the share in high-skilled occupations is similar across the SNR and the LFS samples. By the third round the gap in employment between those in the SNR and the LFS samples had close to seventeen percentage points. Moreover, the gap in the likelihood of being unemployed had close to just six percentage points. Interestingly, closing the gap in employment rates resulted in a bigger gap in the share of workers in high-skilled jobs. The reason is an increase in the number of respondents in the SNR sample who are now in medium and low-skilled level jobs.

[Table 2]

In order to control for other relevant factors that may affect labour market outcomes we estimate a series of probit models along the following lines:

$$
Y_{i}=\delta_{i}+\beta R_{i}+\theta X_{i}+\varepsilon_{i}
$$

Where $Y_{i}$ is the dichotomous outcome of interest, $\delta_{i}$ is a UK region dummy, $R_{i}$ is a dummy indicating that the respondent comes from the SNR sample (i.e. versus the LFS sample) and $X_{i}$ are a series of control variables. In $X_{i}$ we include controls for: age, education, ${ }^{3}$ gender, religion, region of origin and type of accommodation. ${ }^{4}$ We also present separate results by gender. Our coefficient of interest is $\beta$ which reports on the estimated difference between SNR and LFS respondents.

Table 3 presents the means of the control variables. While the characteristics of respondents in the full LFS sample are markedly different from those of respondents in the SNR sample, recent migrants in the LFS have several characteristics in common with refugees in the SNR. The age distribution is very similar as well as the length of stay in the

\footnotetext{
${ }^{3}$ The information on education in the SNR is provided as a categorical variable and there is no information on years of education. Also, in the LFS there is no information on English courses since arrival to the UK that could be used as a comparison with the SNR information on this topic.

${ }^{4}$ The reference category for accommodation is social housing. Living in this type of accommodation can discourage migrants from moving to other areas/regions to take advantage of job opportunities. Excluding homeowners from the analysis leads to results that are similar to those with the recent migrant sample.
} 
UK. Three key differences are gender, religion and region of origin. Respondents in the SNR tend to be overwhelmingly male, more likely to be Muslim and mostly come from Africa. The gender difference is expected as the SNR is a sample of main applicants and women are often classified as dependants in asylum applications. We explore the role of gender in detail below. The religion and geographical aspects reflect the characteristics of the main countries of origin of asylum seekers in the UK. Meanwhile, recent migrants in the LFS are balanced in terms of gender, more likely to be Christian and Europe is the main region of origin. [Table 3]

There are several potential problems with comparing the SNR and LFS. First, there is a decrease in the number of SNR respondents from the first round to the third round and this could lead to attrition bias. It is difficult to know whether attrition would bias the results upwards or downward. In order to explore this possibility we repeat the analysis but only including those who are in all three rounds of the SNR sample (i.e. full panel). These individuals never left the sample and we are therefore able to have consistent results in terms of labour market progression. Second, the LFS includes a large sample of Old EU migrants who might have unobserved characteristics that are better rewarded in the labour market (e.g. familiarity with "Western" culture) and this could lead to biased results. In order to explore this possibility we also present results excluding Old EU migrants from the LFS sample. Third, it is also possible to argue that in order to minimize the chances of those in the LFS sample being refugees themselves it is necessary to drop those who come from the main countries of origin of refugees in the UK. We also conduct this exercise in the robustness section. Fourth, previous studies have highlighted the possibility of selective out-migration from the UK in response to economic fluctuations (Dustmann et al., 2010; Vargas-Silva, 2015). The fact that "unsuccessful” economic migrants are more likely to return home and not being part of the LFS sample suggests that our estimates could be biased against the 
refugee sample. In order to address this possibility we limit the LFS sample to those who have spent five years or more in the UK and are less likely to leave the country during a downturn. Finally, the use of ten years as the threshold to define recent migrants in the LFS sample is arbitrary. In the robustness section we how results using two years in the UK as an alternative definition of recent migrants. While this leads to a substantial decrease in the sample size, it is an interesting comparison as by the third round of the survey most of those in the SNR have spent over two years in the UK and are being compared to more recent migrants in the LFS.

\section{Refugees versus other migrants}

Table 4 reports the impacts of all the variables on the likelihood of being in employment (average marginal effects). Those in the SNR sample are ten percentage points less likely to be in employment in the first round. This gap decreases to five percentage points in the second round (four percentage points compared to recent migrants) and three percentage points for the third round (one percentage point compared to recent migrants). Notice that by the third round the difference with the LFS sample of recent migrants is not statistically significant.

[Table 4]

In the discussion below we only show the average marginal effects for the main variable of interest (i.e. the SNR dummy). However, for completeness in Table 4 we show the average marginal effects for all the control variables. The results are very much as expected. Those who are female, recently arrived and less educated tend to have lower likelihood of being in employment. There are also interesting differences across regions of origin and regions of the UK. With the exception of the Middle East, migrants from other regions of origin are more likely to be in employment than those from Asia. Also, migrants in the North East and Yorkshire and the Humber regions are significantly less likely to be in 
employment than those in London. Those in Scotland, Norther Ireland and the North West have a higher likelihood of employment than those in London if we limit the sample to recent migrants. However, further analysis suggests that regional differences are mainly driven by those in the LFS sample.

Table 5 reports the main results from the analysis for all the outcomes of interest. The reported coefficients are the average marginal effects of the probit model for the variable indicating that the individual is in the SNR sample. While eight months after the initial decision of asylum refugees are seven percentage points more likely to be unemployed this difference decreases over time. In fact, by the third round the SNR-LFS unemployment gap is insignificant for the estimations using both LFS samples. This is broadly consistent with the results for the likelihood of being in employment.

Notice also that for the first round those in the SNR sample who are working are eight percentage points more likely to be in high-skilled jobs. Those refugees in employment at this point are more likely to have network connections and a professional background. As more refugees join the labour market in the following rounds, most going to medium and lowskilled jobs, this difference becomes insignificant.

[Table 5]

The results in Table 4 highlight the key role of gender in explaining labour market outcomes and suggest that females are at a significantly disadvantage relative to males. However, the results in Table 4 do not provide insights on differences in the role of gender across respondents of the SNR and LFS samples. In Table 6 we show the main results regarding employment and unemployment separately by gender.

The results suggest that the SNR-LFS gap in the likelihood of being in employment remains present for the third round of the survey for females only. In fact, for males this gap 
disappears in the second round. As such, refugee women seem to be in a substantial disadvantage relative to other female migrants and refugee men.

One note of caution is necessary in interpreting the results from Table 6. While gender in the LFS is simply a reflection of the demographic composition of the migrant population of the UK, this is not the case in the SNR sample. As explained above, males are over-represented in the SNR sample as this is a sample of main applicants for asylum and females are often in the dependant category. The group of females in the main applicant category could be selected along unobserved characteristics that drive the results in one way or another. Nonetheless, the gender dimension provides interesting insights and the results have important implications for female refugee labour market integration into host societies.

\section{[Table 6]}

\section{Robustness checks}

In Table 7 we present all the robustness checks discussed in the methodology section. In the first panel we present the results if we only include those SNR respondents who were in three rounds of the survey. That is, we only include those in the full panel. We find a significant gap between those in the SNR and LFS samples for the first round, but not from the second round onwards. As such, the convergence in outcomes between those in the SNR and LFS samples does not seem to be driven by attrition and, if anything, there is faster convergence for those in all three rounds of the survey. In the second panel of Table 7 we present the results when we exclude Old EU migrants from the sample. We find less significance in the differences in the third round, but the results do not change much.

[Table 7]

The third panel of Table 7 presents the results when migrants from the key countries of asylum are excluded from the LFS sample. Given data limitations we need to conduct the analysis for the first round using only data from the first to the fourth quarter of 2007 . 
Overall, results are not affected by the exclusion of those from key countries of asylum from the LFS sample.

In the fourth panel we present results if we limit the LFS sample to those migrants who have spent at least five years in the UK. As expected, the differences between those in the SNR and the LFS samples are smaller once we exclude very recent migrants from the LFS sample. In fact, the difference is not significant in any of the three rounds for the likelihood of being in employment, while it becomes insignificant for the likelihood of unemployment in the third round.

Finally, in the last panel we show the results if we define recent migrants in the LFS as those who have been less than two years in the UK. Results for the first period suggest that those in the SNR sample are worse off than those in the LFS. However, by the third period those in the SNR sample are better off in terms of employment and unemployment. Those in the SNR sample are 11 percentage points more likely to be in employment and four percentage points less likely to be unemployed. Keep in mind that in this case we are comparing very recent migrants from the LFS with those in the SNR sample, all of which by this point are likely to have spent over two years in the country. Also, note that the number of observations is substantially smaller than in other estimations and it is not possible to make strong claims from just this result.

\section{Conclusions}

In the coming years, the UK will be hosting a growing number of refugees. It is too early to explore the labour market outcomes of new refugees in the UK and to provide recommendations regarding integration into the labour market. However, it is possible to shed some light on this topic by looking at the labour market dynamics of previous refugee cohorts. In this paper we compare the labour market outcomes of individuals who were granted protection during the $2005-2007$ period to those of other migrants living in the UK at 
the time. We find that eight and fifteen months after the grant of protection, refugees were less likely to be in employment and more likely to be unemployed relative to other migrants. However, twenty-one months after the grant of protection the difference between the two groups becomes smaller and the difference of refugees with recent migrants becomes insignificant.

There are several possible explanations for these dynamics. First, the previous evidence suggests that asylum seekers in the UK are typically provided with accommodation in places in which they do not have full access to ethnic networks that could facilitate the search for employment. However, after obtaining protection they could gradually move closer to ethnic networks. Close to $65 \%$ of the refugees in the sample moved accommodation at least twice during the period of the survey which suggests a high degree of mobility. Also, close to half the refugees stated that they had monthly contact with ethnic groups or organisations after 21 months of the grant of protection. ${ }^{5}$ Second, asylum seekers are generally not allowed to work while their application is being processed and time away from the labour market can lead to deterioration of skills and, at least in the short-term, psychological discouragement. Studies in order contexts show that just a few months of inactivity can lead to a serious decline in skills and that recovery takes substantial time and effort.

Our findings have implications for asylum seeker dispersal policies and the right to work of asylum seekers in the UK. The differences between the outcomes at 8, 15 and 21 months suggest that early access to networks and the labour market could lead to faster convergence to the economic outcomes of other migrants. Early access to networks and the labour market will also allow refugees to support themselves and contribute to the local economy.

\footnotetext{
${ }^{5}$ This information is not available for 8 and 15 months after the grant for protection.
} 
It is important to note some caveats and limitations to our study. First, we are using information from two different surveys. We demonstrate the robustness of the results to several potential problems in the comparison between surveys, but concerns always remain. Second, we do not have information past twenty-one months after the asylum decision to explore if the outcomes of refugees simply converge to those of other migrants or if the outcomes of refugees are better than those of other migrants in the long-term. Third, we do not have comparable information on variables such language skills, which are important to understand labour market integration. Fourth, we look at a period of economic deceleration (i.e. mid-2000s). The adjustment of refugees and differences with other migrant groups could be different in other economic contexts. Finally, our results are for a particular cohort of refugees and a particular time period. Nothing says that the dynamics of future refugees (e.g. Syrian refugees) will be similar to the ones in our sample. 


\section{References}

Ager, A. and A. Strang (2008) "Understanding Integration: A Conceptual Framework" Journal of Refugee Studies, 21(2): 166 - 191.

Allsopp, J., Sigona, N. and J. Phillimore (2014) "Poverty Among Refugees and Asylum Seekers in the UK: An Evidence and Policy Review” IRiS Working Paper Series, No. $1 / 2014$.

Bloch, A. (2004) "Labour Market Participation and Conditions of Employment: A Comparison of Minority Ethnic Groups and Refugees in Britain” Sociological Research Online, 9(2).

Bloch, A. (2007) "Refugees in the UK Labour Market: The Conflict between Economic Integration and Policy-led Labour Market Restriction” Journal of Social Policy, 37(1): 21 36.

Borjas, G.J. (1987) "Self-Selection and the Earnings of Immigrants" The American Economic Review, 77(4): 531-553.

Cafferty P.S.J., Chiswick B.R., Greeley A.M., Sullivan, T.A. (1983) The Dilemma of American Immigration: Beyond the Golden Door. Transaction Publishers.

Campbell, M. (2012) "Social Determinants of Mental Health in New Refugees in the UK: Cross-section and Longitudinal Analyses” The Lancet, 380(3): S27.

Campbell, S. (2014) "Does it Matter Why Immigrants Came Here? Original Motives, the Labour Market, and National Identity in the UK”, Department of Quantitative Social Science, University of London, Working Paper No. 14-14.

Cebulla, A., Daniel, M. and Zurawan, A. (2010) "Spotlight on Refugee Integration: Findings from the Survey of New Refugees in the United Kingdom” London: Home Office.

Cheung, S.Y. and Phillimore, J. (2014) "Refugees, Social Capital, and Labour Market Integration in the UK” Sociology, 48(3): 518-536.

Chiswick, B.R. (1999) “Are Immigrants Favorably Self-Selected?” The American Economic Review, 89(2), 181-185.

Cooper, J., Campbell, S., Patel, D. and J. Simmons (2014) “The Reason for Migration and Labour Market Characteristics of UK Residents Born Abroad” Home Office, Occasional Paper 110.

Cortes, K.E. (2004) “Are Refugees Different from Economic Immigrants? Some Empirical Evidence on the Heterogeneity of Immigrant Groups in the United States" The Review of Economics and Statistics, 86(2): 465-480.

Damm, A.P. (2009) "Ethnic Enclaves and Immigrant Labor Market Outcomes: QuasiExperimental Evidence” Journal of Labor Economics, 27(2): 281-314. 
Daniel, M., Devine, C., Gillespie, R., Pendry, E. and Zurawan, A. (2010) "Helping New Refugees Integrate into the UK: Baseline Data Analysis from the Survey of New Refugees" London: Home Office.

Dustmann C., Glitz A., Vogel T. (2010) "Employment, Wages, and the Economic cycle: Differences between Immigrants and Natives” European Economic Review, 54: 1-17.

Edin, P., Fredriksson, P. and Aslund, O. (2003) "Ethnic Enclaves and the Economic Success of Immigrants-Evidence from a Natural Experiment” Quarterly Journal of Economics, 118: 329-357.

Fransen, S., Ruiz, I. and Vargas-Silva, C. (2015) "Return Migration and Economic Outcomes in the Conflict Context” Households in Conflict Network, Working Paper 203.

General Medical Council (2014) "Skills Fade: A Review of the Evidence that Clinical and Professional Skills Fade During Time Out of Practice, and of How Skills Fade may be Measured or Remediated”. Retrieved 2 may 2016 and available at http://www.gmcuk.org/Skills_fade_literature_review_final_Report.pdf_60956354.pdf.

Gower, M. (2016) “Should Asylum Seekers Have Unrestricted Rights to Work in the UK?” Briefing Paper, 1908. House of Commons Library.

Home Office (2016) “Immigration Statistics, October to December 2015”. Retrieved 2 May 2016 and available at https://www.gov.uk/government/statistics/immigration-statisticsoctober-to-december-2015.

Kausar, R. and Drinkwater, S. (2010) "A Comparison of Earnings and Occupational Attainment of Refugees and Asylum Seekers and Economic Immigrants in the UK" Department of Economics, University of Surrey, 08/10.

Lindley, J.K. (2000) "Economic Assimilation and the Labour Market Performance of British Refugees and Economic Migrants” Research Paper Series Globalisation and Labour Markets Programme, 2002/06.

Muus, P. (1997) "Shifting Borders: the Inclusion and Exclusion of Refugees and AsylumSeekers in the Netherlands". In Muus, P. (ed.) Exclusion and Inclusion of Refugees in Contemporary Europe. Utrecht: Netherlands.

Phillimore, J. and Goodson, L. (2006) "Problem or Opportunity? Asylum Seekers, Refugees, Employment and Social Exclusion in Deprived Urban Areas” Urban Studies, 43(10): 1-22.

Platts-Fowler, D. and Robinson, D. (2015) “A Place for Integration: Refugee Experiences in Two English Cities” Population, Space and Place, 21: 476-491.

Raaum, O. and Røed, K. (2006) "Do Business Cycle Conditions at the Time of Labor Market Entry Affect Future Employment Prospects" The Review of Economics and Statistics, 88(2): 193-210.

Stewart, E.S. (2012) "UK Dispersal Policy and Onward Migration: Mapping the Current State of Knowledge” Journal of Refugee Studies, 25(1): 25-49. 
Vargas-Silva, C. (2015) "Highly Skilled Migrant Workers and the UK Business Cycle." Population, Space and Place, forthcoming.

Zetter, R., Griffiths, D. and Sigona, N. (2005) “Social Capital or Social Exclusion? The Impact of Asylum-Seeker Dispersal on UK Refugee Community Organizations” Community Development Journal, 40(2), 169-181. 
Appendix 1 - Variables included in the estimations.

\begin{tabular}{ll}
\hline Variable & \multicolumn{1}{c}{$\begin{array}{c}\text { Definition and construction } \\
\text { Dependent variables }\end{array}$} \\
\hline In employment & $\begin{array}{l}\text { Equal to } 1 \text { if the person is in employment, 0 otherwise. SNR: based on question about } \\
\text { main activity in the UK. LFS: based on INECAC05 category (basic economic } \\
\text { activity/ILO definition). Includes those who are employees (including those in } \\
\text { government employment and training programmes) or self-employed. }\end{array}$ \\
& $\begin{array}{l}\text { Equal to } 1 \text { if the person is in unemployed, 0 otherwise. SNR: based on question about } \\
\text { main activity in the UK. LFS: based on INECAC05 category (basic economic } \\
\text { activity/ILO definition). }\end{array}$ \\
& $\begin{array}{l}\text { Equal to } 1 \text { if the person is in a high-skilled occupation, 0 otherwise. Information only } \\
\text { available for those in employment. High-skilled occupations are defined as those in the } \\
\text { top three categories of the Standard Occupational Classification (SOC) (i.e. Managers }\end{array}$ \\
and Senior Officials, Professional occupations, Associate Professional and Technical). \\
SNR: based on question on occupation in the UK. The dataset already includes a match \\
of response with the SOC. LFS: based on SC2KMMJ (major occupation group for main \\
job).
\end{tabular}

Independent

Female

Equal to 1 if gender is reported as female, 0 otherwise.

Age 18-24

Equal to 1 if the person is in this age range, 0 otherwise.

Age 25-34

Equal to 1 if the person is in this age range, 0 otherwise.

Age 35-44

Equal to 1 if the person is in this age range, 0 otherwise.

Age 45-64

Equal to 1 if the person is in this age range, 0 otherwise. 
Less than 2 years in UK

2 to 5 years in UK

Over 5 years in UK

Home owner

Private rent

Christian

Muslim

Education $=0$ years

$0<$ years of education $<10$
Equal to 1 if the person has spent less than two years in the UK, 0 otherwise. SNR: Given the information about length of stay in the country it is possible to shift people to other categories for the second and third round. LFS: constructed using CAMEYR (year of first arrival to the UK).

Equal to 1 if the person has spent from two to five years in the UK, 0 otherwise. SNR: Given the information about length of stay in the country it is possible to shift people to other categories for the second and third round. LFS: constructed using CAMEYR (year of first arrival to the UK).

Equal to 1 if the person has spent over five years in the UK, 0 otherwise. SNR: Given the information about length of stay in the country it is possible to shift people to other categories for the second and third round. LFS: constructed using CAMEYR (year of first arrival to the UK).

Equal to 1 if the person lives in a house own by a household member, 0 otherwise.

Equal to 1 if the person lives in private rental accommodation, 0 otherwise.

Equal to 1 if the person reported Christianity as religion, 0 otherwise.

Equal to 1 if the person reported Islam as religion, 0 otherwise.

Equal to 1 if the person had no education on arrival to the UK, 0 otherwise. SNR: information is asked directly to respondents. LFS: constructed using information on age, year of arrival and age at which the person completed full time education (EDAGE).

Equal to 1 if the person has some education, but less that ten years in total upon arrival to the UK, 0 otherwise. SNR: information is asked directly to respondents. LFS: constructed using information on age, year of arrival and age at which the person completed full time education (EDAGE). 
$10 \leq$ years of education $\leq 16$

Years of education $>16$

Africa

Americas

Asia

Europe

Middle East

Dummies for region of the UK
Equal to 1 if the person has from ten to sixteen years of education in total upon arrival to the UK, 0 otherwise. SNR: information is asked directly to respondents. LFS: constructed using information on age, year of arrival and age at which the person completed full time education (EDAGE).

Equal to 1 if the person has more than sixteen years of education in total upon arrival to the UK, 0 otherwise. SNR: information is asked directly to respondents. LFS: constructed using information on age, year of arrival and age at which the person completed full time education (EDAGE).

Equal to 1 if region of origin is Africa, 0 otherwise. SNR: based on question about "country of origin". LFS: based on country of birth.

Equal to 1 if region of origin is the Americas, 0 otherwise. SNR: based on question about "country of origin”. LFS: based on country of birth. Includes North America, South America and Caribbean.

Equal to 1 if region of origin is Europe, 0 otherwise. SNR: based on question about "country of origin”. LFS: based on country of birth. It does not include Oceania.

Equal to 1 if region of origin is Europe, 0 otherwise. SNR: based on question about “country of origin”. LFS: based on country of birth. Includes EU and non-EU countries.

Equal to 1 if region of origin is the Middle East, 0 otherwise. SNR: based on question about “country of origin”. LFS: based on country of birth.

Defined as 1) London and South East, 2) East Midlands, West Midlands and East of England, 3) North East, Yorkshire and the Humber, 4) Wales and South West, 5) Scotland, Northern Ireland and North West. 
Table 1 - Equivalent LFS sample for each SNR round.

\begin{tabular}{lcccc}
\hline SNR round & $\begin{array}{c}\text { SNR respondents } \\
\text { (refugees) }\end{array}$ & $\begin{array}{c}\text { LFS quarters used } \\
\text { for comparison }\end{array}$ & $\begin{array}{c}\text { LFS all respondents } \\
\text { (other migrants) }\end{array}$ & $\begin{array}{c}\text { LFS recent respondents } \\
\text { (other migrants) }\end{array}$ \\
\hline 1 & 1,555 & Q3 2006 to Q4 2007 & 9,999 & 4,818 \\
2 & 1,111 & Q1 2007 to Q2 2008 & 10,238 & 4,942 \\
3 & 839 & Q3 2007 to Q4 2008 & 10,507 & 5,120 \\
In all three SNR rounds & 729 & & &
\end{tabular}

Notes: "LFS recent” refers to the sample of other migrants (non-refugees) who have been in the UK for 10 years or less. 
Table 2 - Labour market outcome of those in the SNR and LFS samples.

\begin{tabular}{lccc}
\hline Outcome & $\begin{array}{c}\text { SNR } \\
\text { (refugees) }\end{array}$ & $\begin{array}{c}\text { LFS all } \\
\text { (other migrants) }\end{array}$ & $\begin{array}{c}\text { LFS recent } \\
\text { (other migrants) }\end{array}$ \\
\hline In employment & 0.40 & Panel1: Round 1 \\
Unemployed & 0.23 & 0.68 & 0.68 \\
High-skilled job & 0.38 & 0.05 & 0.06 \\
& & 0.43 & 0.36 \\
In employment & 0.47 & Panel 2: Round 2 & \\
Unemployed & 0.16 & 0.68 & 0.69 \\
High-skilled job & 0.32 & 0.05 & 0.06 \\
& & 0.43 & 0.36 \\
In employment & 0.51 & Panel 3: Round 3 & \\
Unemployed & 0.11 & 0.68 & 0.69 \\
High-skilled job & 0.29 & 0.05 & 0.05 \\
\hline
\end{tabular}

Notes: all variables are dummies in which yes $=1$, no $=0$. "LFS recent" refers to the sample of other migrants (non-refugees) who have been in the UK for 10 years or less. High-skilled job is only available for those who are working. Please see the appendix for details on the construction of each variable. 
Table 3 - Descriptive statistics of control variables.

\begin{tabular}{lccc}
\hline Variable & $\begin{array}{c}\text { SNR } \\
\text { (refugees) }\end{array}$ & $\begin{array}{c}\text { LFS all } \\
\text { (other migrants) }\end{array}$ & $\begin{array}{c}\text { LFS recent } \\
\text { (other migrants) }\end{array}$ \\
\hline Male & 0.65 & 0.48 & 0.49 \\
Female & 0.35 & 0.52 & 0.51 \\
Age 18-24 & 0.19 & 0.12 & 0.20 \\
Age 25-34 & 0.45 & 0.30 & 0.48 \\
Age 35-44 & 0.25 & 0.26 & 0.23 \\
Age 45-64 & 0.11 & 0.31 & 0.09 \\
Less than 2 years in UK & 0.40 & 0.20 & 0.41 \\
2 to 5 years in UK & 0.34 & 0.15 & 0.31 \\
Over 5 years in UK & 0.25 & 0.66 & 0.29 \\
Home owner & 0.04 & 0.51 & 0.27 \\
Private rent & 0.29 & 0.33 & 0.58 \\
Christian & 0.45 & 0.50 & 0.55 \\
Muslim & 0.42 & 0.21 & 0.18 \\
Education $=0$ years & 0.10 & 0.09 & 0.00 \\
$0<$ years of education $<10$ & 0.22 & 0.13 & 0.02 \\
$10 \leq$ years of education $\leq 16$ & 0.49 & 0.50 & 0.55 \\
Years of education $>16$ & 0.20 & 0.29 & 0.42 \\
Europe & 0.09 & 0.34 & 0.40 \\
Americas & 0.01 & 0.09 & 0.08 \\
Africa & 0.53 & 0.20 & 0.19 \\
Middle East & 0.25 & 0.03 & 0.03 \\
Asia & 0.12 & 0.34 & 0.31 \\
\hline Not Val & & 0.34
\end{tabular}

Notes: Values for the SNR first follow-up round and equivalent LFS comparison sample. Estimations also include dummies for UK region. All variables are dummies in which yes $=1$, no $=0$. "LFS recent" refers to the sample of other migrants (non-refugees) who have been in the UK for 10 years or less. Please see the appendix for details on the construction of each variable. 
Table 4 - Estimated differences in likelihood of being in employment between those in the SNR (refugee) vs. LFS (other migrants) samples.

\begin{tabular}{|c|c|c|c|c|c|c|}
\hline \multirow{2}{*}{$\begin{array}{l}\text { Independent } \\
\text { variables }\end{array}$} & \multicolumn{2}{|c|}{ Round 1} & \multicolumn{2}{|c|}{ Round 2} & \multicolumn{2}{|c|}{ Round 3} \\
\hline & LFS all & LFS recent & LFS all & LFS recent & LFS all & LFS recent \\
\hline SNR sample & $\begin{array}{c}-0.10 * * * \\
(-7.37)\end{array}$ & $\begin{array}{c}-0.10 * * * \\
(-6.00)\end{array}$ & $\begin{array}{c}-0.05 * * * \\
(-3.45)\end{array}$ & $\begin{array}{c}-0.04 * * \\
(-2.18)\end{array}$ & $\begin{array}{l}-0.03^{*} \\
(-1.68)\end{array}$ & $\begin{array}{c}-0.01 \\
(-0.55)\end{array}$ \\
\hline Female & $\begin{array}{c}-0.21 * * * \\
(-28.11)\end{array}$ & $\begin{array}{c}-0.24 * * * \\
(-23.79)\end{array}$ & $\begin{array}{c}\text { Gender o } \\
-0.22^{* * *} \\
(-28.60) \\
\text { Age om }\end{array}$ & $\begin{array}{c}\text { ted: male } \\
-0.23^{* * *} \\
(-22.49) \\
d: 18-24\end{array}$ & $\begin{array}{c}-0.22 * * * \\
(-29.39)\end{array}$ & $\begin{array}{c}-0.22 * * * \\
(-21.73)\end{array}$ \\
\hline Age $25-34$ & $\begin{array}{c}0.13^{* * * *} \\
(9.90)\end{array}$ & $\begin{array}{c}0.12 * * * \\
(8.23)\end{array}$ & $\begin{array}{c}0.15^{* * *} \\
(11.55)\end{array}$ & $\begin{array}{c}0.14 * * * \\
(10.00)\end{array}$ & $\begin{array}{c}0.16^{* * *} \\
(12.22)\end{array}$ & $\begin{array}{c}0.16^{* * *} \\
(10.69)\end{array}$ \\
\hline Age $35-44$ & $\begin{array}{c}0.13^{* * *} \\
(9.53)\end{array}$ & $\begin{array}{c}0.11^{* * *} \\
(6.60)\end{array}$ & $\begin{array}{c}0.14^{* * *} \\
(9.91)\end{array}$ & $\begin{array}{c}0.13^{* * *} \\
(7.49)\end{array}$ & $\begin{array}{c}0.14^{* * *} \\
(9.62)\end{array}$ & $\begin{array}{c}0.12 * * * \\
(7.08)\end{array}$ \\
\hline \multirow[t]{2}{*}{ Age $45-64$} & $\begin{array}{c}0.06 * * * \\
(4.47)\end{array}$ & $\begin{array}{c}0.07 * * * \\
(3.43)\end{array}$ & $\begin{array}{c}0.07 * * * \\
(5.21)\end{array}$ & $\begin{array}{c}0.09 * * * \\
(4.26)\end{array}$ & $\begin{array}{c}0.07 * * * \\
(4.68)\end{array}$ & $\begin{array}{c}0.09 * * * \\
(4.21)\end{array}$ \\
\hline & \multicolumn{6}{|c|}{ Time in the UK omitted: over 5 years } \\
\hline Less than 2 years & $\begin{array}{c}-0.07 * * * \\
(-5.44)\end{array}$ & $\begin{array}{c}-0.11 * * * \\
(-7.31)\end{array}$ & $\begin{array}{c}-0.05 * * * \\
(-3.85)\end{array}$ & $\begin{array}{c}-0.09 * * * \\
(-6.36)\end{array}$ & $\begin{array}{c}-0.05^{* * * *} \\
(-3.20)\end{array}$ & $\begin{array}{c}0.09 * * * \\
(-5.54)\end{array}$ \\
\hline 2 to 5 years & $\begin{array}{c}0.00 \\
(0.14)\end{array}$ & $\begin{array}{c}-0.02 \\
(-1.50)\end{array}$ & $\begin{array}{c}0.01 \\
(0.50)\end{array}$ & $\begin{array}{l}-0.03^{*} \\
(-1.71)\end{array}$ & $\begin{array}{c}-0.00 \\
(-0.11)\end{array}$ & $\begin{array}{c}-0.03^{* *} \\
(-2.22)\end{array}$ \\
\hline \multicolumn{7}{|c|}{ Accommodation omitted: other housing (e.g. social housing) } \\
\hline Home owner & $\begin{array}{c}0.26 * * * \\
(24.33)\end{array}$ & $\begin{array}{c}0.25^{* * *} \\
(15.03)\end{array}$ & $\begin{array}{c}0.25 * * * \\
(23.80)\end{array}$ & $\begin{array}{c}0.23 * * * \\
(13.22)\end{array}$ & $\begin{array}{c}0.25 * * * \\
(23.18)\end{array}$ & $\begin{array}{c}0.20 * * * \\
(11.73)\end{array}$ \\
\hline Private rent & $\begin{array}{c}0.19 * * * \\
(16.66)\end{array}$ & $\begin{array}{l}0.19 * * * \\
(13.74)\end{array}$ & $\begin{array}{c}0.16^{* * *} \\
(14.09)\end{array}$ & $\begin{array}{c}0.15 * * * \\
(10.27)\end{array}$ & $\begin{array}{c}0.16 * * * \\
(13.65)\end{array}$ & $\begin{array}{c}0.14 * * * \\
(9.34)\end{array}$ \\
\hline & \multicolumn{6}{|c|}{ Religion omitted: other (e.g. Hinduism) } \\
\hline Christian & $\begin{array}{c}0.04 * * * \\
(3.95)\end{array}$ & $\begin{array}{c}0.06 * * * \\
(4.23)\end{array}$ & $\begin{array}{c}0.04 * * * \\
(3.51)\end{array}$ & $\begin{array}{c}0.07 * * * \\
(4.35)\end{array}$ & $\begin{array}{c}0.04 * * * \\
(4.24)\end{array}$ & $\begin{array}{c}0.08 * * * \\
(5.33)\end{array}$ \\
\hline Muslim & $\begin{array}{c}-0.15^{* * *} \\
(-13.66)\end{array}$ & $\begin{array}{c}-0.13^{* * *} \\
(-7.73)\end{array}$ & $\begin{array}{c}-0.17 * * * \\
(-15.20)\end{array}$ & $\begin{array}{c}-0.14^{* * *} \\
(-8.56)\end{array}$ & $\begin{array}{c}-0.17 * * * \\
(-14.85)\end{array}$ & $\begin{array}{c}-0.15^{* * *} \\
(-9.12)\end{array}$ \\
\hline & \multicolumn{6}{|c|}{ Education omitted: above 16 years } \\
\hline None & $\begin{array}{c}-0.00 \\
(-0.09)\end{array}$ & $\begin{array}{c}-0.16^{* * *} \\
(-3.98)\end{array}$ & $\begin{array}{l}-0.03^{*} \\
(-1.82)\end{array}$ & $\begin{array}{c}-0.04 \\
(-0.74)\end{array}$ & $\begin{array}{c}-0.03 \\
(-1.62)\end{array}$ & $\begin{array}{c}-0.07 \\
(-1.28)\end{array}$ \\
\hline 0 to 9 years & $\begin{array}{c}-0.04 * * * \\
(-2.71)\end{array}$ & $\begin{array}{c}-0.09 * * \\
(-2.36)\end{array}$ & $\begin{array}{c}-0.04 * * * \\
(-2.73)\end{array}$ & $\begin{array}{c}-0.08 * * * \\
(-3.29)\end{array}$ & $\begin{array}{c}-0.05 * * * \\
(-3.15)\end{array}$ & $\begin{array}{c}-0.13^{* * *} \\
(-4.85)\end{array}$ \\
\hline 10 to 16 years & $\begin{array}{c}-0.03 * * * \\
(-2.79)\end{array}$ & $\begin{array}{l}-0.07^{*} \\
(-1.70)\end{array}$ & $\begin{array}{c}-0.05 * * * \\
(-4.61)\end{array}$ & $\begin{array}{c}-0.04 * * * \\
(-3.13)\end{array}$ & $\begin{array}{c}-0.06 * * * \\
(-5.69)\end{array}$ & $\begin{array}{c}-0.05 * * * \\
(-3.96)\end{array}$ \\
\hline $\mathrm{LR} \chi^{2}$ & $2,625.11$ & $1,702.29$ & $2,391.36$ & $1,452.17$ & $2,230.52$ & $1,342.15$ \\
\hline Pseudo $R^{2}$ & 0.17 & 0.20 & 0.16 & 0.18 & 0.16 & 0.18 \\
\hline Observations & 11,554 & 6,373 & 11,349 & 6,053 & 11,346 & 5,959 \\
\hline
\end{tabular}


Table 4 continuation - Estimated differences in likelihood of being in employment.

\begin{tabular}{lcccccc}
\hline Independent & \multicolumn{2}{c}{ Round 1 } & \multicolumn{2}{c}{ Round 2 } & \multicolumn{2}{c}{ Round 3 } \\
variables & LFS all & LFS recent & LFS all & LFS recent & LFS all & LFS recent \\
\hline & & \multicolumn{3}{c}{ Region of origin omitted: Asia } \\
Europe & $0.10^{* * *}$ & $0.14^{* * *}$ & $0.10^{* * *}$ & $0.13^{* * *}$ & $0.06^{* * *}$ & $0.08^{* * *}$ \\
& $(8.81)$ & $(8.58)$ & $(8.54)$ & $(8.21)$ & $(5.01)$ & $(5.02)$ \\
Americas & $0.06^{* * *}$ & 0.04 & $0.07^{* * *}$ & $0.06^{* *}$ & $0.04^{* *}$ & -0.01 \\
& $(3.72)$ & $(1.61)$ & $(4.16)$ & $(2.32)$ & $(2.50)$ & $(-0.57)$ \\
Africa & $0.08^{* * *}$ & $0.05^{* * *}$ & $0.07^{* * *}$ & 0.01 & $0.05^{* * *}$ & -0.01 \\
& $(6.48)$ & $(2.91)$ & $(5.53)$ & $(0.80)$ & $(3.88)$ & $(-0.61)$ \\
Middle East & -0.01 & -0.02 & -0.02 & $-0.06^{* *}$ & $-0.06^{* * *}$ & $-0.11^{* * *}$ \\
& $(-0.64)$ & $(-0.93)$ & $(-1.27)$ & $(-2.51)$ & $(-2.95)$ & $(-4.33)$ \\
East M, West & 0.01 & $0.03^{* *}$ & -0.01 & 0.01 & $-0.02^{*}$ & -0.00 \\
M, Eastern & $(0.80)$ & $(2.40)$ & $(-1.35)$ & $(0.70)$ & $(-1.65)$ & $(-0.24)$ \\
North East, & $-0.04^{* * *}$ & $-0.05^{* * *}$ & $-0.04^{* * *}$ & $-0.04^{* *}$ & $-0.04^{* * *}$ & $-0.04^{* *}$ \\
Yorkshire/Hum & $(-3.00)$ & $(-2.64)$ & $(-2.83)$ & $(-2.08)$ & $(-2.90)$ & $(-2.11)$ \\
Wales, & $0.03^{*}$ & 0.03 & 0.01 & 0.02 & 0.02 & 0.03 \\
South West & $(1.73)$ & $(1.55)$ & $(0.62)$ & $(0.79)$ & $(1.06)$ & $(1.08)$ \\
Scotland, NI, & 0.01 & $0.04^{*}$ & 0.01 & $0.04 *$ & -0.00 & 0.02 \\
North West & $(0.62)$ & $(1.82)$ & $(0.57)$ & $(1.77)$ & $(-0.02)$ & $(0.87)$ \\
LR $\chi^{2}$ & $2,625.11$ & $1,702.29$ & $2,391.36$ & $1,452.17$ & $2,230.52$ & $1,342.15$ \\
Pseudo $R^{2}$ & 0.17 & 0.20 & 0.16 & 0.18 & 0.16 & 0.18 \\
Observations & 11,554 & 6,373 & 11,349 & 6,053 & 11,346 & 5,959 \\
\hline
\end{tabular}

Notes: Coefficients are the average marginal effects from a probit model. * indicates significant at the $10 \%$ level, $* *$ indicates significant at the $5 \%$ level and $* * *$ indicates significant at the $1 \%$ level. $\mathrm{t}$ statistics are included in parenthesis. 
Table 5 - Estimated difference in labour market outcomes of those in the SNR (refugee) vs. LFS (other migrants) samples.

\begin{tabular}{lcccccc}
\hline \multirow{2}{*}{ Outcome } & \multicolumn{2}{c}{ Round 1 } & \multicolumn{2}{c}{ Round 2 } & \multicolumn{2}{c}{ Round 3 } \\
& LFS all & LFS recent & LFS all & LFS recent & LFS all & LFS recent \\
\hline \multirow{2}{*}{ In employment } & $-0.10^{* * *}$ & $-0.10^{* * *}$ & $-0.05^{* * *}$ & $0.04^{* *}$ & $-0.03^{*}$ & -0.01 \\
& $(-7.37)$ & $(-6.00)$ & $(-3.46)$ & $(-2.21)$ & $(-1.68)$ & $(-0.55)$ \\
Unemployed & $0.07^{* * *}$ & $0.08^{* * *}$ & $0.04^{* * *}$ & $0.04^{* * *}$ & 0.01 & 0.01 \\
Observations & $(9.59)$ & $(8.31)$ & $(5.42)$ & $(3.70)$ & $(0.82)$ & $(1.24)$ \\
High-skilled job & 11,554 & 6,373 & 11,349 & 6,053 & 11,346 & 5,959 \\
Observations & $0.08^{* * *}$ & $0.07^{* *}$ & 0.01 & 0.03 & -0.01 & 0.02 \\
\hline & $(2.72)$ & $(2.03)$ & $(0.35)$ & $(0.97)$ & $(-0.34)$ & $(0.59)$ \\
\hline
\end{tabular}

Notes: Coefficients are the average marginal effects from a probit model of the coefficient indicating that the individual is in the SNR (refugee) sample. * indicates significant at the $10 \%$ level, $* *$ indicates significant at the $5 \%$ level and $* * *$ indicates significant at the $1 \%$ level. $\mathrm{t}$ statistics are included in parenthesis. High-skilled job is only available for those who are working. 
Table 6 - Estimated difference in labour market outcomes of those in the SNR (refugee) vs. LFS (other migrants) samples by gender.

\begin{tabular}{|c|c|c|c|c|c|c|}
\hline \multirow{2}{*}{ Outcome } & \multicolumn{2}{|c|}{ Round 1} & \multicolumn{2}{|c|}{ Round 2} & \multicolumn{2}{|c|}{ Round 3} \\
\hline & LFS all & LFS recent & LFS all & LFS recent & LFS all & LFS recent \\
\hline & \multicolumn{6}{|c|}{ Panel 1: Females } \\
\hline In employment & $\begin{array}{c}-0.12 * * * \\
(-5.00)\end{array}$ & $\begin{array}{c}-0.08 * * * \\
(-2.67)\end{array}$ & $\begin{array}{c}-0.10^{* * * *} \\
(-3.61)\end{array}$ & $\begin{array}{c}-0.07 * * \\
(-2.10)\end{array}$ & $\begin{array}{c}-0.10 * * * \\
(-3.43)\end{array}$ & $\begin{array}{l}-0.06^{*} \\
(-1.73)\end{array}$ \\
\hline & $0.06 * * *$ & $0.07 * * *$ & $0.04^{* * *}$ & $0.04^{* * *}$ & -0.01 & 0.00 \\
\hline Unemproyed & $(5.30)$ & $(4.67)$ & $(3.29)$ & (2.59) & $(-0.96)$ & $(-0.11)$ \\
\hline Observations & 5,763 & 2,993 & 5,776 & 2,928 & 5,880 & 2,948 \\
\hline & \multicolumn{6}{|c|}{ Panel 2: Males } \\
\hline In employment & $\begin{array}{c}-0.10 * * * \\
(-6.11)\end{array}$ & $\begin{array}{c}-0.11 * * * \\
(-5.51)\end{array}$ & $\begin{array}{c}-0.03 \\
(-1.49)\end{array}$ & $\begin{array}{c}-0.02 \\
(-1.04)\end{array}$ & $\begin{array}{c}0.02 \\
(0.85)\end{array}$ & $\begin{array}{c}0.02 \\
(0.85)\end{array}$ \\
\hline Unemployed & $\begin{array}{c}0.08^{* * * *} \\
(7.74)\end{array}$ & $\begin{array}{c}0.09 * * * \\
(6.46)\end{array}$ & $\begin{array}{c}0.04^{* * * *} \\
(3.75)\end{array}$ & $\begin{array}{c}0.03 * * \\
(2.12)\end{array}$ & $\begin{array}{c}0.01 \\
(0.81)\end{array}$ & $\begin{array}{c}0.01 \\
(0.58)\end{array}$ \\
\hline Observations & 5,791 & 3,380 & 5,573 & 3,125 & 5,466 & 3,011 \\
\hline
\end{tabular}

Notes: Coefficients are the average marginal effects from a probit model of the coefficient indicating that the individual is in the SNR (refugee) sample. * indicates significant at the $10 \%$ level, ${ }^{* *}$ indicates significant at the $5 \%$ level and $* * *$ indicates significant at the $1 \%$ level. $t$ statistics are included in parenthesis. 
Table 7 - Estimated difference in labour market outcomes of those in the SNR (refugee) vs. LFS (other migrants) samples: robustness checks

\begin{tabular}{|c|c|c|c|c|c|c|}
\hline \multirow{2}{*}{ Outcome } & \multicolumn{2}{|c|}{ Round 1} & \multicolumn{2}{|c|}{ Round 2} & \multicolumn{2}{|c|}{ Round 3} \\
\hline & LFS all & LFS recent & LFS all & LFS recent & LFS all & LFS rece \\
\hline & \multicolumn{6}{|c|}{ Panel 1: Only including those in the three rounds of the SNR sample } \\
\hline \multirow{2}{*}{ In employment } & $-0.10^{* * *}$ & $-0.09 * * *$ & -0.02 & -0.00 & -0.01 & 0.01 \\
\hline & $(-5.69)$ & $(-4.23)$ & $(-1.25)$ & $(-0.12)$ & $(-0.48)$ & $(0.52)$ \\
\hline \multirow{2}{*}{ Unemployed } & $0.06^{* * *}$ & $0.07^{* * *}$ & $0.03^{* * *}$ & $0.03^{* * *}$ & 0.00 & 0.01 \\
\hline & $(7.62)$ & $(6.28)$ & $(4.18)$ & $(2.57)$ & $(0.27)$ & $(0.82)$ \\
\hline \multirow[t]{2}{*}{ Observations } & 10,722 & 5,541 & 10,967 & 5,671 & 11,236 & 5,849 \\
\hline & \multicolumn{6}{|c|}{ Panel 2: Excluding those from Old EU countries from LFS sample } \\
\hline \multirow{2}{*}{ In employment } & $-0.11^{* * *}$ & $-0.10 * * *$ & $-0.05 * * *$ & $-0.03^{*}$ & -0.03 & -0.01 \\
\hline & $(-7.23)$ & $(-5.85)$ & $(-2.80)$ & $(-1.81)$ & $(-1.56)$ & $(-0.40)$ \\
\hline \multirow{2}{*}{ Unemployed } & $0.07^{* * *}$ & $0.09 * * *$ & $0.04^{* * *}$ & $0.04^{* * *}$ & 0.01 & 0.01 \\
\hline & $(9.19)$ & (7.97) & $(4.95)$ & $(3.32)$ & $(0.72)$ & (1.04) \\
\hline \multirow[t]{2}{*}{ Observations } & 9,248 & 5,283 & 8,759 & 4,672 & 8,805 & 4,596 \\
\hline & \multicolumn{6}{|c|}{ Panel 3: Excluding those from the main countries of asylum from LFS sample } \\
\hline \multirow{2}{*}{ In employment } & $-0.11^{* * *}$ & $-0.11 * * *$ & $-0.06 * * *$ & $-0.06^{* * *}$ & $-0.03^{*}$ & -0.02 \\
\hline & $(-7.07)$ & $(-5.97)$ & $(-4.06)$ & $(-3.03)$ & $(-1.78)$ & $(-1.01)$ \\
\hline \multirow{2}{*}{ Unemployed } & $0.08^{* * *}$ & $0.10^{* * *}$ & $0.04^{* * *}$ & $0.04^{* * *}$ & 0.01 & 0.01 \\
\hline & $(8.43)$ & (7.14) & $(5.30)$ & (3.55) & $(0.75)$ & (1.13) \\
\hline \multirow[t]{2}{*}{ Observations } & 7,952 & 4,581 & 10,798 & 5,700 & 10,795 & 5,598 \\
\hline & \multicolumn{6}{|c|}{ Panel 4: Only including those who have spent five years or more in the UK in the LFS sample } \\
\hline \multirow{2}{*}{ In employment } & -0.02 & & -0.01 & & -0.02 & \\
\hline & $(-1.29)$ & & $(-0.68)$ & & $(-0.92)$ & \\
\hline \multirow{2}{*}{ Unemployed } & $0.05^{* * *}$ & & $0.03^{* * *}$ & & -0.00 & \\
\hline & (5.23) & & (3.79) & & $(-0.27)$ & \\
\hline \multirow[t]{2}{*}{ Observations } & 8,579 & & 8,408 & & 8,331 & \\
\hline & \multicolumn{6}{|c|}{ Panel 5: Only including those who have been less than two years in the UK in the LFS sample } \\
\hline \multirow{2}{*}{ In employment } & & $-0.16^{* * *}$ & & $-0.22 * *$ & & $0.11^{* * *}$ \\
\hline & & $(-5.02)$ & & $(-1.97)$ & & (2.93) \\
\hline \multirow{3}{*}{ Unemployed } & & $0.13^{* * *}$ & & 0.13 & & $-0.04 *$ \\
\hline & & $(5.08)$ & & $(0.97)$ & & \\
\hline & & 2,782 & & 2.183 & & \\
\hline
\end{tabular}

Notes: Coefficients are the average marginal effects from a probit model of the coefficient indicating that the individual is in the SNR (refugee) sample. * indicates significant at the $10 \%$ level, ** indicates significant at the $5 \%$ level and $* * *$ indicates significant at the $1 \%$ level. $t$ statistics are included in parenthesis. Old EU: pre-2004 EU member states. Main countries of asylum are Eritrea, Somalia, Afghanistan, Iran, Zimbabwe and the Democratic Republic of 
Figure 1 - Grants of protection in the UK by region of origin.

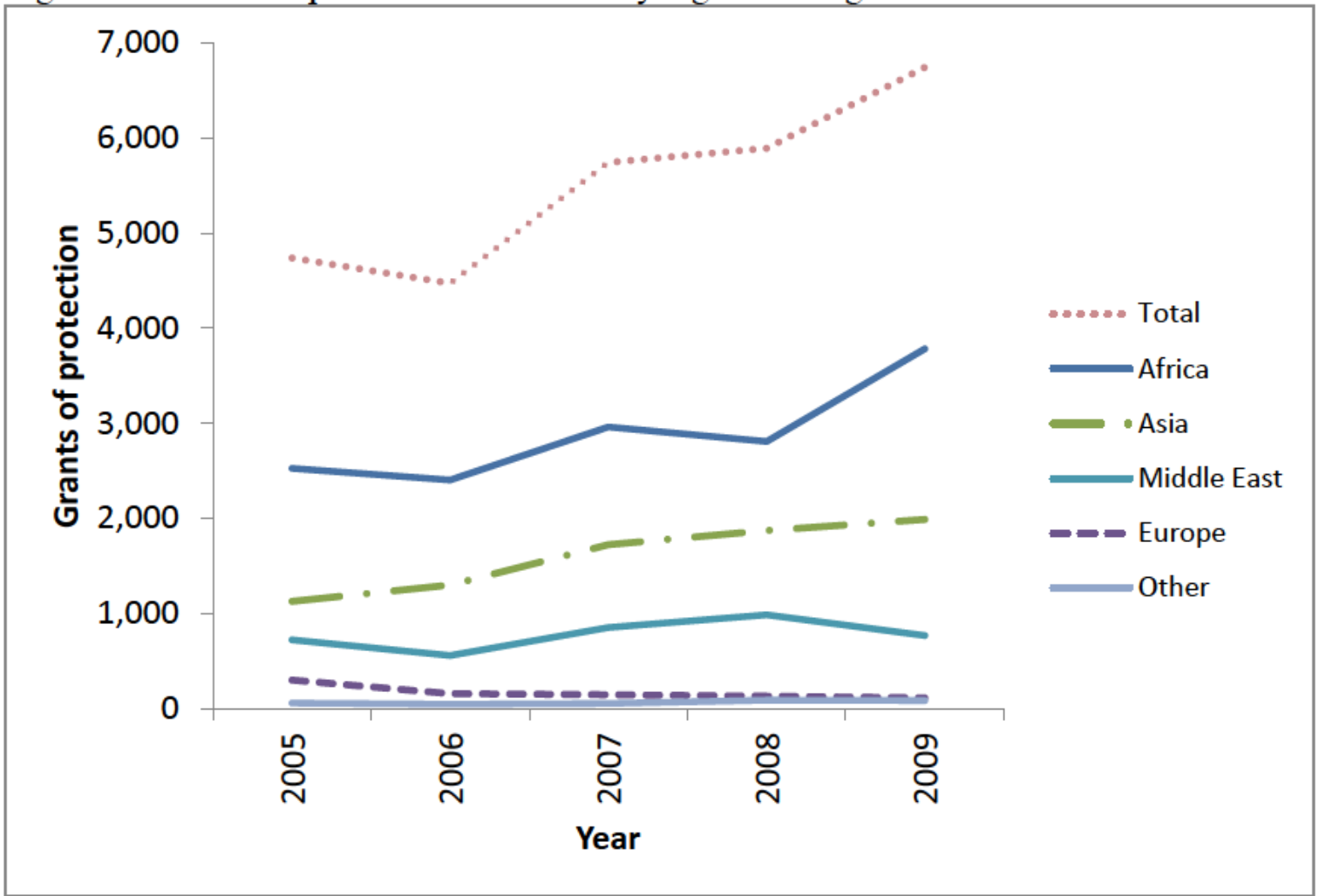

Note: source is the UK Home Office Migration Statistics. 
Figure 2 - Employment rates: UK and non-UK born individuals.

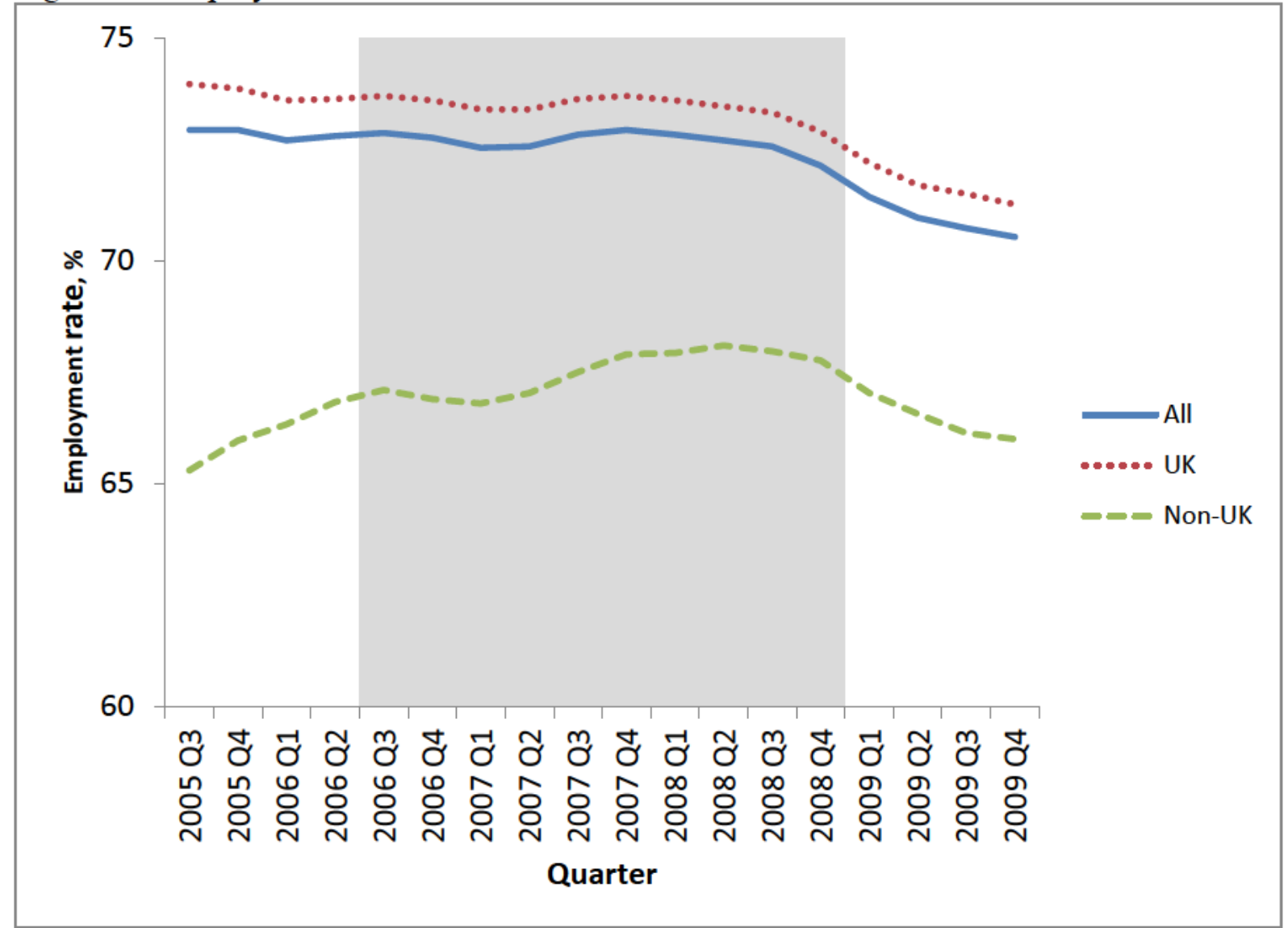

Note: source is the Office of National Statistics labour market series statistics. It only includes individuals of working age. Not seasonally adjusted. Series presented is a 3-month average. 